\title{
O encontro entre dança e educação somática como uma interface de questionamento epistemológico sobre as teorias do corpo

Resumo: Neste artigo, destaco a sinergia entre a educação somática e a dança, como um subespaço de produção de conhecimento qualificado sobre o corpo. Considero que as práticas de educação somática possibilitaram novos caminhos de investigação e criação, alterando profundamente os modos de fazer dança, para além da clássica epistemologia mecanicista em que se pauta o treinamento corporal tradicional. Minha hipótese é de que essa zona híbrida entre arte e ciência vem desestabilizando concepçôes importantes, tais como memória, cognição, movimento, hábito, natureza, cultura, entre outros, produzindo importantes subsídios na direção de novas epistemologias sobre o corpo.

Palavras-chave: dança; educação somática; corpo; epistemologia.

\section{The encounter of dance and somatic education as a new epistemological} interface on body theories

Abstract: This article focuses on the collaboration between somatic education and dance as a sub-space for production of qualified knowledge on the body. It is argued that the practices of somatic education have provided new kinds of investigation and creation, making significant changes in the ways of making dance and producing new aesthetic concepts that present other ideas than the ones from the classical mechanist epistemology. Our hypothesis is that this hybrid zone between art and science has been mobilizing important conceptions, such as memory, cognition, movement, habit, nature, and culture, among others, producing an important support for new epistemologies on the body.

Key words: dance; somatic education; body; epistemology.

\section{O nascimento de uma interface de conhecimento}

A educação somática é um campo emergente de conhecimento de natureza interdisciplinar que surgiu no século $\mathrm{XX}$, protagonizado por profissionais das

* Professora do Instituto de Humanidades, Artes e Ciências Professor Milton Santos e do Programa de Pós-Graduação em Artes Cênicas da Universidade Federal da Bahia, artista da dança e pesquisadora de estudos do corpo e estudos da mestiçagem nas artes cênicas. domeniceloisa@gmail.com; http://www.ppgac.tea.ufba.br; www.ihac.ufba.br. 
áreas da saúde, da arte e da educação. Esse campo surgiu inicialmente fora da academia e vem sendo trazido para as universidades paulatinamente, embora uma boa parcela da pesquisa seja ainda hoje realizada fora destas e de forma pouco sistematizada. Embora a natureza desse campo tenha como uma marca forte o empirismo, devido ao próprio início de sua história, a partir de um determinado momento, a sistematização e a reflexão tornaram-se fundamentais. Nesse sentido, o seu ingresso nas universidades vem contribuindo muito para a sua consolidação como campo de conhecimento.

O campo compreende diversos métodos de trabalho corporal, na sua maioria criados na Europa e nos Estados Unidos no início do século XX, propondo novas abordagens do movimento, a partir de pressupostos que divergem da visão mecanicista do corpo. Os seus criadores, muitos deles motivados pelo desejo de curar-se, rejeitando as respostas oferecidas pela ciência dominante, passaram a investigar o movimento nos seus próprios corpos (Strazzacappa, 2006). Assim, esses pioneiros, Moshe Feldenkrais (Método Feldenkrais), Ingmar Bartenieff (Método Bartenieff), Gerda Alexander (Eutonia), Matthias Alexander (Técnica de Alexander), Ida Rolf (Rolfing), Mabel Todd (Ideokinesis), Bonnie Bainbridge-Cohen (Body-Mind Centering), entre outros, criaram suas teorias baseadas em suas próprias experiências. Seus métodos mostraram-se eficientes e logo foram disseminados por seus discípulos nas décadas seguintes.

Como se dá o movimento no corpo? Quais as relaçōes entre corpo e mente? O que é a percepção e como ela opera? Quais as relaçôes entre a percepção e o movimento no corpo? Qual a importância das emoçōes nesse circuito? Essas eram algumas das perguntas para as quais esses pioneiros formularam respostas inovadoras.

Nos anos 1960, esse novo campo de experimentação sobre o corpo ampliou-se ainda mais, graças ao maior interesse de artistas da dança por tais métodos. Um primeiro resultado desse encontro com a dança foi o próprio encontro entre métodos diferentes, que antes ocupavam nichos isolados, nos ateliês e nas escolas de seus criadores, e que agora eram trazidos para dentro dos estúdios de dança.

O encontro com a educação somática deu-se em um momento muito especial, em que ocorria uma saturação dos modelos da dança moderna e do preciosismo da forma. Esse encontro provocou importantes mudanças na maneira de pensar o corpo na dança: reivindicou o respeito aos limites anatômicos do corpo, estimulou a exploração de novos padrões de movimento e questionou modelos e concepções bastante firmadas pela tradição acerca do treinamento corporal. 
A norte-americana Ann Halprin, considerada uma musa revolucionária da geração da chamada Judson Church $^{1}$, propunha aos seus alunos exercícios, tais como explorar o movimento de cada articulação isolada, o que hoje pode parecer muito comum, mas na época soava muito diferente das aulas de técnica de dança. Halprin falava em subverter a lógica de organização do movimento corporal e de explorar uma lógica de organização animal, acreditando no "movimento desconhecido que dorme na cartografia das dinâmicas corporais"; o corpo deveria ser "livre e compreendido em relação de seus mecanismos próprios" (Louppe, 1994, p. 99, grifo nosso). Essa mudança que ocorreu, do tradicional modelo de observação e cópia do movimento para protocolos de investigação do seu próprio corpo, foi a grande virada que "expandiu os territórios do imaginário e do sensível" e fundou uma nova filosofia do movimento, que revolucionou a dança nas décadas seguintes, como analisa a historiadora Laurence Louppe (1994).

A partir desse momento, os métodos de educação somática passaram a ser frequentemente experimentados, agora não apenas por indivíduos que buscavam saúde e bem-estar, mas também por pessoas interessadas em produzir arte com o seu corpo, ganhando uma nova contribuição diferenciada e bastante dedicada: a dos artistas da dança.

Para a dança, os impactos foram muito determinantes, não somente em termos das práticas educacionais, mas também da estética. A experimentação e a improvisação ganharam grande status, desta vez muito diferente do que propunha Isadora Duncan nos anos 1920. Ao invés de servir ao transbordamento das emoções, a improvisação agora interessava como método para investigar novos padrōes de movimento, que eram manejados experimentalmente como novos repertórios. Ao invés do romantismo das emoções, o foco agora era a materialidade do corpo e do movimento. Essa liberação semiótica ${ }^{2}$ da dança, que já havia sido iniciada por Merce Cunninghan, seria determinante para o futuro. Falava-se em um lugar branco, sem memória e sem desejo, capaz de descondicionar a linguagem da dança das leituras psicologizantes. O movimento tinha inventado um estado de liberdade irreversível na sua qualidade de objeto destacado da ordem do mundo.

Os novos métodos de trabalho corporal, obviamente, não foram a única contribuição importante para essas mudanças que acabaram por detonar a se-

I. Judson Church é o nome pelo qual ficou conhecido o Judson Dance Theater, que funcionou como um polo de nascimento do pós-modernismo na dança.

2. Libertação semiótica da dança diz respeito ao reconhecimento do movimento como signo, em sua materialidade, e não como simples veículo de sentimentos ou histórias. Semelhante ao que ocorreu na literatura com a poesia concreta. 
mente do pós-modernismo na dança, mas foram determinantes, na medida em que provocaram mudanças nos processos que subsidiam o corpo.

A educadora Sylvie Fortin, professora do Departamento de Dança da Université du Québec à Montréal, que vem se dedicando a estudar a dinâmica do campo da educação somática, publicou, em 2002, um balanço sobre os seus reflexos nas práticas educacionais de dança, apontando também as adaptações locais que as práticas experimentam em cada cultura diferente.

Minha intenção aqui é propor um outro tipo de balanço: a contribuição dessa experiência acumulada em termos de conhecimento sobre o corpo. Nesse sentido, a sinergia gerada pelo encontro da educação somática com a dança, no meu modo de ver, contribuiu decisivamente, na medida em que a ousadia estética da dança possibilitou um novo campo experimental para a educação somática, enquanto esta forneceu subsídios importantes para que os coreógrafos pudessem materializar a expansão desejada. $\mathrm{O}$ intuito deste artigo é o de destacar o potencial desse encontro particular, que não deixa de ser um encontro da ciência com a arte, para a consolidação de novas epistemologias sobre o corpo.

\section{Ciências cognitivas}

A partir da década de 1960, algo importante viria a ocorrer também na ciência. Trata-se das pesquisas sobre a cognição humana. Os estudos sobre a visão começaram a produzir dados que abalavam profundamente as crenças sobre como o ser humano constrói o conhecimento sobre o mundo. Mostrou-se que a visão não é um fenômeno passivo, de captação da imagem dos objetos do mundo, mas, sim, uma construção do cérebro na interação com esses objetos, no qual participam, além da informação visual, outros tipos de dados, como tato, cheiro, sons e também experiências da memória. Essas pesquisas tiveram implicações filosóficas determinantes. A existência de uma realidade objetiva ficou seriamente abalada e a subjetividade passou a estar necessariamente implicada na construção de qualquer tipo de conhecimento. Este foi o começo do que mais tarde viria a se tornar, nos anos 1980-90, uma corrente téorica denominada embodied cognition, segundo a qual a experiência corporal (sensório-motora) é a base para a construção de qualquer tipo de conhecimento.

A ciência chegava a conclusões muito importantes: o corpo está diretamente implicado no conhecimento do mundo - a maneira como se experiencia o mundo interfere determinantemente no que se conhece. Então, uma vez que experiência é algo individual, que pode ser compartilhada apenas parcialmente, é impossível uniformizar o conhecimento de cada corpo diante do mesmo objeto ou evento. Corpo não é um ambiente passivo que reage ao mundo de 
maneira sempre previsível; é um ambiente ativo que constrói novos conhecimentos e comportamentos na interação com o mundo, em tempo real.

Proposições como essa, que a ciência apenas recentemente passou a aceitar, já vinham sendo testadas na prática no campo da educação somática, há décadas, o mesmo ocorrendo com temas como consciência, memória, aprendizado, dentre outros, para as quais já se aceitavam proposiçôes igualmente distantes da ciência clássica.

Contribuindo para uma epistemologia sobre o corpo

Para a ciência clássica, o conhecimento produzido experimentalmente nas práticas de educação somática não é totalmente válido porque é carregado de subjetividade. A objetividade consiste em tratar o corpo como um objeto, falando dele em terceira pessoa ${ }^{3}$.

A educação somática define corpo não como um objeto, mas como um processo corporificado de consciência interna e comunicação ${ }^{4}$ (Green, 2002, p. 114). Em certo ponto da história, os educadores somáticos tentaram nomear essa diferença, propondo o termo soma $a^{5}$ em lugar de corpo. Thomas Hanna define assim o conceito de soma:

O corpo percebido a partir de si mesmo, como percepção em primeira pessoa. Quando o ser humano é percebido de fora, do ponto de vista de um terceiro, o fenômeno do corpo humano é percebido.... O soma, sendo percebido internamente, écategoricamente distinto de um corpo, não porque o sujeito é diferente, mas porque o modo de percepção é diferente - éa propriocepção imediata - um modo de sensação que fornece dados únicos. (Hanna apud Fortin, 2002, p. 128 - tradução nossa)

3. Esta posição da ciência, no entanto, não abrange todos os cientistas, como é o caso do neurologista norte-americano Oliver Sachs, que publicou diversos livros contendo relatos de seus pacientes em primeira pessoa e comentários seus, relacionando esses sinais às próprias patologias, que são verdadeiras lições de semiologia do corpo vivo. Ao contrário de serem considerados absurdos ou inócuos, os relatos são tratados por Sachs com curiosidade e respeito pelas informações que aqueles indivíduos podem agregar ao conhecimento das neuropatologias. $\bigcirc$ fato de serem experiências subjetivas não as desqualifica em termos de conhecimento, simplesmente agrega as informações que aquele sujeito está percebendo no seu corpo e que só podem ser relatadas por ele. Ver SACHS, Oliver, (200 I) O homem que confundiu sua mulher com um chapéu.

4. Tradução nossa do texto original: An embodied process of internal awareness and communication (Green, 2002, p. 114).

5. Thomas Hanna define assim o conceito de soma: The body as perceived from within by first person perception. When a human being is observed from the outside, i.e., from a third-person viewpoint, the phenomenon of a human body is perceived... The soma, being internally perceived, is categorically distinct from a body, not because the subject is different but because the mode of viewpoint is different: it is immediate proprioception - a sensor mode that provide unique data. (Hanna apud Fortin, 2002, p. 128). 
Essa proposta de mudar a nomenclatura não modificou o hábito de utilizar o termo corpo, mostrando que, na verdade, é a concepção de corpo o que importa.

A educação somática trabalha com uma concepção de corpo que se aproxima da idéia de processo. Entretanto, alguns textos da área ainda mesclam outras metáforas típicas do dualismo cartesiano, tais como instrumento ou veículo ${ }^{6}$. Tais metáforas carregam ideias muito diferentes sobre a natureza do corpo e os seus modos de operar. Este é um descompasso que precisa ser superado para que a pesquisa avance.

O campo da educação somática vem se expandindo muito nas últimas décadas, sendo que a transformação é um fenômeno atual do campo (Fortin, 2002). Além da disseminação dos primeiros métodos (Alexander, 1991; Bartenieff, 1980; Doud, 1996; Feldenkrais, 1972; Todd, 1980; Vishnivetz, 1995.) uma série de novas práticas já foram criadas e outras ainda surgiram pela hibridação de métodos já existentes, ainda mais singularizadas pelas diferenças culturais.

No Brasil, destacam-se duas propostas de educação somática bastante originais: de Klauss Vianna e de José Antônio Lima. Klauss Vianna e seus colaboradores, Angel e Rainer Vianna, criaram uma proposta que destaca a pressão sobre os apoios (resistência), as oposições musculares, espaços articulares e direçōes ósseas (Miller, 2007; Neves, 2008). Lima, ex-aluno e assistente de Vianna, desenvolveu a proposta denominada Reorganização Postural Dinâmica (Lima, 2010), utilizando o trabalho muscular lento e contínuo contra uma resistência oferecida pelo próprio corpo. Tanto Vianna quanto Lima criaram suas propostas trabalhando com um público composto, em sua maioria, por dançarinos e atores; portanto, já se trata da sinergia com as artes do corpo, expansão que é fruto do encontro do qual estamos falando.

Dada a expansão e a transformação do campo, não é simples analisar o que se vem produzindo de conhecimento sobre o corpo nessa interface. Mesmo assim, a seguir, procurarei destacar alguns princípios organizadores ${ }^{7}$ mais comuns nas práticas de educação somática, apontando concordâncias e discordâncias com ideias correntes nas ciências cognitivas e ainda destacando criadores que estão testando essas ideias em sua dança.

6. No mesmo texto em que Jill Green concorda com a visão de Thomas Hanna sobre soma, alguns parágrafos adiante ele afirma que "o corpo é um veículo por meio do qual o dançarino se expressa" (Green, 2002, p. I I4, grifo nosso), e mais adiante: como o corpo é um instrumento humano (op cit, p. 117 , grifo nosso). As metáforas veículo e instrumento são claramente dualistas e contradizem a ideia de processo.

7. Fortin (1998) propõe a expressão "princípios organizadores fundamentais", referindo-se a conceitos pessoais básicos de conhecimento do assunto que orientam as ações do professor e explicam as razões dessas ações. 
Um princípio geral das práticas de educação somática é privilegiar a informação que vem do próprio corpo para orientar as decisões. O caminho mais notável foi a investigação das possibilidades do movimento pela exploração da sensopercepção, o que se tornou comum chamar de "consciência corporal". Daí se complementa esse princípio organizador: a busca do refinamento sensorial e a crença de que ele aumenta as possibilidades de escolha, ou seja, aumenta a liberdade do criador (Fortin, 1996).

$\mathrm{O}$ trabalho de refinamento sensorial inclui exercícios para aprender a reconhecer as informaçôes que vêm do próprio corpo; portanto, é um aprendizado que privilegia o sentido da propriocepção. Nas aulas de dança influenciadas pela educação somática, ao invés de copiar um modelo, o aluno aprende a trabalhar com parâmetros, tais como as posiçôes relativas entre os ossos e as articulações, os estados tônicos dos grupamentos musculares, a situação dos seus apoios, entre outros. Este se tornou um princípio muito comum nas abordagens técnicas baseadas em investigação do movimento. Mesmo se o professor propõe alguma frase de movimento para estudo, este procedimento é apenas uma etapa no aprendizado. Em uma etapa seguinte o aluno é estimulado a improvisar, utilizando aqueles movimentos aprendidos e criando novos encadeamentos. O objetivo é que o aluno descubra como ele se move e como pode se mover, tornando-se investigador do seu próprio movimento e conquistando uma posição de autonomia.

Desde a geração da Judson Church e a sua rebeliāo contra a ditadura da forma, as práticas educacionais de dança baseadas na exploração da sensopercepção ganharam destaque. À época, a situação geral era de descrença em uma regra que viesse "de fora" e de busca de uma organização que viesse "de dentro" do próprio corpo. Desde então, isso se transformou em jargão no discurso da dança, muitas vezes ainda contaminado pelo emocionalismo das fases romântica e expressionista ${ }^{8}$.

Não só se modificaram as práticas pedagógicas, mas também se expandiram os limites da dança para além da semanticidade, explorando agora a materialidade do corpo. A exploração do movimento como matéria, que pode ser manipulado nele mesmo, sem se prender ao "que ele quer dizer", reafirmou o status da dança como uma arte autônoma; não mais um instrumento de representação do drama, como ocorria no balé, nem da música, como no romantismo. Com isso, a dança saiu da representação e passou à apresentação, uma categoria completamente diferente, como explicaremos adiante.

8. Tanto a dança romântica quanto a expressionista acreditam no dualismo entre o sentimento, localizado no interior do indivíduo, e a forma, expressa no exterior do corpo. A função da dança seria de exteriorizar os sentimentos. Por isso o jargão de que "a dança expressa o que vem de dentro". 
O termo consciência corporal passou a ser usado de maneira bastante disseminada desde os pioneiros da educação somática (como em Awareness through movement, Feldenkrais, 1972), termo este que, por sua vez, está relacionado a outra ideia bastante consolidada no campo da educação somática: a do corpo inteligente ${ }^{9}$.

Consciência corporal e inteligência do corpo são termos que, embora tragam no seu bojo a ideia de corpo como ambiente vivo e produtor de nova informação, como vem sendo bastante debatido nas ciências cognitivas, podem gerar uma ilusão de controle voluntário em tempo integral.

A consciência é um dos problemas centrais das ciências cognitivas e conta com uma extensa literatura. Vale a pena comentar apenas uma ideia bastante aceita, de que existem variados níveis de consciência, onde se destacam a autoconsciência ou consciência de alta ordem, dependente do relato da linguagem - o sujeito é capaz de dizer "eu sei que tal coisa está ocorrendo" - consciousnes. Já a consciência inferior ou primária, independe do relato da linguagem awareness —, e pode ser equivalente ao estado de alerta ou prontidão ${ }^{10}$.

Ao invés de pensar numa inteligência que estaria só no corpo ou só na mente, importantes autores das ciências cognitivas adotam a ideia do continuum corpomente e defendem que a experiência sensório-motora ocupa papel central nos processos cognitivos. Essa é a corrente teórica denominada embodied cognition (Damásio, 1996; 1998; Lakoff Johnson, 1999.). Alguns autores desse grupo ainda defendem a ideia de corpo como um processo evolutivo capaz de auto-organizar comportamentos de alta ordem de elaboração mediante os estímulos apropriados, graças à sua complexidade e capacidade de interação inteligente com o ambiente; não de maneira determinista, como na concepção behaviorista de estímulo-resposta, mas de maneira complexa, em que as respostas emergem ${ }^{11}$ em tempo real (Thelen e Smith, 1994).

Este é o caso da psicóloga norte-americana Esther Thelen (1941-2004), que se especializou no estudo do desenvolvimento psicomotor de crianças. Para

9. Essa ideia está bem expressa nos livros: The thinking body, de Mabel Todd (1932) e The use of self, de Moshe Feldenkrais (1937), e também no meio da dança, como mostra o dossiê da revista belga Contradanse, de 1996, dedicado ao assunto da educação somática, cujo texto de abertura se denomina L'intelligence du corps.

10. A consciência inferior faz-se com fluxo de imagens. Para uma introdução sobre o assunto, há alguns autores de obras de divulgação das ciências cognitivas, tais como António Damásio (2000) e Gerald Edelman, (1992). Vale ressaltar que essa identificação da consciência corporal como awareness está presente na educação somática desde os pioneiros, como em Awareness through movement (Feldenkrais, 1972).

1।. The idea of emergence - the temporary but coherent coming into existence of new forms through ongoing processes intrinsic to the system - is fundamental to the idea of dynamic systems (Smith, 2006, p. 87). 
esta autora, os padrões de movimento não surgem de um plano ou programa $a$ priori: eles emergem no sistema no momento em que uma situação acontece, como resultado da interação entre as possibilidades do corpo e os desafios do ambiente ${ }^{12}$. Engatinhar, por exemplo, é um padrão coerente de movimento que as crianças usam para se locomover quando já têm força e coordenação suficientes para ficar em quatro apoios sobre as mãos e os joelhos e ainda não têm equilíbrio e força suficientes para ficar em pé. Não há programa para engatinhar no código genético ou pré-organizado no sistema nervoso. Esse padrão de movimento se auto-organiza como uma solução temporária para o problema (atravessar uma sala) e é substituído mais tarde por uma solução mais eficiente. Quando a criança aprende a andar, aquele padrão perde estabilidade para os padrões de ficar em pé e caminhar. Embora a coordenação desenvolvida para engatinhar sirva como substrato para coordenar a marcha em pé, o desenvolvimento é muito mais uma série de padrōes que surgem e desaparecem com graus variados de estabilidade do que uma marcha inevitável para a maturidade (Smith, 2006, p. 87). Essa é a explicação da chamada corrente dinamicista, para a qual a "inteligência do corpo" é uma propriedade intrínseca do sistema corpomente, que não depende do controle de um sujeito ou de um plano elaborado antes da situação, mas acontece pela auto-organização de comportamentos em tempo real.

$\mathrm{O}$ interesse pela emergência e imprevisibilidade passou a estar presente também nas artes do corpo. Criadores explicitam essa propriedade do corpo vivo, de interagir com o ambiente em tempo real, levando para o palco situações de interatividade onde várias decisōes ocorrem no momento da apresentação, como no espetáculo Modo de fazer, da Cia. Dani Lima (2006).

O princípio organizador que privilegia a sensopercepção está baseado em um paradigma muito importante sobre o corpo: movimento não é só ação - é ação e percepção atuando em contínuo.

A maioria dos treinamentos técnicos para dança entendem o movimento de acordo com a epistemologia mecanicista do corpo, tomando o movimento como sinônimo de ação, ou seja, o evento visível que resulta de um comando cerebral previamente aprendido, agindo sobre a periferia do corpo (organização topdown). A ação tem uma direção única, do centro para a periferia. Já as práticas

12. Complex systems composed of very many individual elements embedded within, and open to a complex environment can exibit coherent behavior: the parts are coordenatd without an executive agent, plan or program. Rather, the coherence is generated solely by the relationships between the organic components and the constraints and opportunities offered by the environment. (Smith, 2006, p. 87). Thelen mostrou que comportamentos tais como andar e alcançar objetos podem ser entendidos como o produto de múltiplos componentes interagindo no "aqui e agora" das tarefas em tempo real. 
de educação somática evidenciam a importância dos fenômenos que ocorrem no sentido inverso (organização bottom-up), chamando a atenção para o fato de que os processos que ocorrem na periferia do corpo alteram o comando central, resultando em interações complexas e novos modos de organização, de maneira muito mais dinâmica do que se pensava ${ }^{13}$.

Esse entendimento é um divisor de águas no reino das práticas pedagógicas de dança. Para o primeiro paradigma (mecanicista), a repetição é o principal método para se aprender um movimento. Para o segundo paradigma (que eu chamarei de dinamicista ou sistêmico), a autopercepção é fundamental para obter maior competência no movimento e a melhora da performance. A repetição "mecânica" do movimento, ao contrário, pode levar a um automatismo que diminui a autopercepção. Assim, busca-se um tipo de repetição que estimule a aprendizagem da dança, capaz de manter os sentidos bem vivos (Fortin, 1998).

O entendimento é o de que ação e percepção são dois lados da mesma moeda. Existe ação na própria percepção, na medida em que a percepção é ativa. Busca-se uma repetição que estimule manter a atenção presente durante a ação.

Outro princípio organizador das práticas de educação somática e que foi introduzido nas aulas de dança é a reeducação postural, seja para a prevenção de lesōes ou para a melhora do movimento de dança. O esforço repetitivo sobre estruturas inadequadamente alinhadas, causando linhas de força incompatíveis com as propriedades funcionais dos tecidos, habitua o organismo a trabalhar contra forças perpendiculares ao eixo de direção do movimento, provocando um gasto de energia desnecessário, que reduz a eficiência do movimento e pode provocar lesōes ao longo do tempo, principalmente nos exaustivos treinamentos baseados na repetição.

Reeducar o alinhamento postural não é tarefa fácil, uma vez que as rotinas de organização das musculaturas antigravitacionais começam a ser treinadas e definidas desde muito cedo. Voltar a atenção para os eventos relacionados à organização da postura é uma empreitada longa e árdua, que irá enfrentar,

13. A respeito da aquisição de habilidades motoras, duas teorias sobre controle e aprendizagem rivalizaram-se na década de 70: o debate centralista versus periferalista, cujo foco principal estava na diferença acerca do papel do feedback no controle de movimentos. Para a teoria periferalista, a informação sensorial durante a execução do movimento é crucial. De acordo com Tani et al (2004), hoje há consenso de que há fatores tanto centrais como periféricos no controle de movimentos, interferindo em maior ou menor grau, dependendo do tipo de movimento lento ou balístico. Ressaltamos que os estudos se concentram no campo da educação física, sendo que a dança pode contribuir de maneira muito diferenciada, como, por exemplo, no que se refere ao tipo de tarefa analisada: os protocolos de educação física analisam tarefas simples, enquanto os protocolos de dança envolvem tarefas muito mais complexas.

Pro-Posiçōes, Campinas, v. 21, n. 2 (62), p. 69-85, maio/ago. 2010 
inclusive, a impaciência do aluno, que acreditava já ter resolvido esse problema com uma série de rotinas sensório-motoras automatizadas durante vários anos.

As práticas de educação somática produziram inúmeros protocolos sobre alinhamento postural, os quais mereceriam estudos aprofundados acerca da dinâmica dos reflexos que mantêm a postura. Uma estratégia que é frequentemente usada para desestabilizar automatismos é propor tarefas sensório-motoras que desafiem os condicionamentos. Por exemplo: caminhar lentamente de modo a dirigir a pressão dos pés contra o chão, em uma linha reta, desde o calcanhar até a linha média do metatarso e artelhos (como proposto por Lima, 1994). Essa nova indicação provoca uma instabilidade no padrão do andar, levanta novos problemas e pede novas soluções. Ao cabo do tempo, esse treinamento pode levar a uma mudança no padrão do movimento do andar.

Outra característica marcante das práticas de educação somática, que também encontra consonância nas configurações contemporâneas de dança, é a valorização do comportamento singular. $\mathrm{O}$ modo individual de organizar o movimento, a memória autobiográfica e única, o movimento singular de um dançarino, são atributos que ganham destaque. $\mathrm{Na}$ dança surge a danse d'auteur (Bentivoglio, 1989 apud Fortin 1998), intransferível e única, bem como coreógrafos à procura de dançarinos com técnica não limitada a um estilo ou mesmo sem "rastros" de estilo".

Profissionais que aplicam princípios da educação somática, entre artistas ou não, valorizam as diferentes soluçôes de cada indivíduo e salientam esse aspecto como uma fonte de aprendizado incessante (Miller, 2007; Vishnivetz, 1995, entre outros). Em termos epistemológicos, a explosão de possibilidades de protocolos vindos dessas hibridaçóes tende a explicitar o fato de que o corpo se comporta de maneiras diferentes, dependendo do que experimenta e como experimenta.

Neurocientistas renomados vêm mostrando que a memória, ao invés de conjunto de arquivos congelados e estocados, é plástica e dinâmica, re-organiza-se mediante cada nova informação (Edelman, 1992). É uma memória criativa. O novo pressuposto é de que não exista um comportamento único e ideal, mas, sim, comportamentos variados mediante uma série de fatores que, projetados ao infinito, tendem à singularidade. Já não é possível projetar pontos de chegada, apenas tendências e probabilidades. A ideia mais importante é o corpo como um sistema dinâmico, um ambiente vivo em transformação constante e pouco previsível. Não existem leis e, sim, regularidades; além disso, os

14. Problematiza-se a questão de uma "técnica sem estilo", que seria um meio para que seja alcançada uma execução ótima de qualquer estilo de dança, assim como o mito da neutralidade corporal e da polivalência motriz, que tendem a ser superados. 
sistemas estão sempre sujeitos a bifurcações (Prigogine e Stengers, 1997). Portanto, não existe uma única verdade válida sobre o corpo e o movimento, mas uma gama complexa de estados diferentes dentro de caminhos evolutivos muito singulares (Thelen e Smith, 1994).

Outra característica marcante dentre as práticas de educação somática é o interesse pelas emoções e o estudo dos seus efeitos no corpo e no movimento. O resultado disso foi dar existência material às emoções de maneira corporificada, o que representa uma conquista em termos de expressão. As emoções deixam de ser etéreas e desencarnadas, como na dança romântica eram fenômenos $d a$ alma, para ganhar uma existência encarnada, como sendo fenômenos do circuito que envolve o continuum corpomente. $\mathrm{O}$ estudo das emoçôes configurase como a qualificação dos estados tônicos do corpo. A dança chamada pósmoderna apresentou maneiras para superar o uso representativo e caricatural das emoçôes, explorando no corpo esses estados tônicos e dando outras maneiras para as emoçôes expressarem-se em cena, não como características ligadas a um sujeito. Exemplos recentes estão nos trabalhos Corpo desconhecido, de Cíntia Kunifas (2004); Impermanências, de Vera Sala (2005); O banho, de Martha Soares (2003) e Encarnado, de Lia Rodrigues (2007).

Em termos semióticos, em relação à produção de linguagem, isso significou muito. Quando também a emoção deixa de ser uma representação, o corpo deixa de representar e passa a apresentar estados corporais que criam empatia e comunicam devido aos próprios traços materiais, estabelecendo uma espécie de diálogo tônico (Godard, 1990).

Em termos da pedagogia da dança, passam a interessar a modulação do esforço e o estudo dos estados tônicos, como qualificadores do movimento. Isso significa que a aula de dança não se interessa mais apenas por padrões de movimento, mas também pelas qualidades tônicas do corpo, sendo estas consideradas um aspecto importante das estratégias que um corpo utiliza para apresentar a dança e comunicar-se.

Com todos esses novos pressupostos, o próprio entendimento do que seja movimento entra em xeque. Enquanto no ballet e na dança moderna, movimento era sinônimo de amplas viagens angulares dos segmentos corporais e/ou de grandes deslocamentos pelo espaço, agora a noção de movimento deve incluir também micromovimentos articulares ou a simples modificação dos estados tônicos do corpo. Modificaçōes sutis provocadas pela modulação da musculatura tônico-gravitacional podem ser lidas como movimento, desafiando a percepção. Não podemos esquecer a contribuição de estéticas surgidas no oriente que passaram a interessar à dança ocidental, notadamente a dança Butoh (Greiner, 1998). 
As configurações contemporâneas de dança revelam uma ampla gama de experimentaçôes, algumas delas propositalmente limiares, radicais por excelência, apresentando um corpo que se comporta de maneira marcadamente diferente em relação a um traço específico, desestabilizando o senso comum. Podemos dizer, de maneira geral, que dança é o que emerge como estratégia de um corpo para comunicar-se, na medida em que surgem experimentos que consistem em provocar alguma modificação no corpo e ver de que maneira ele se comunica nessa nova situação, seja essa modificação feita por próteses (como Alexandro Ahmed); seja criando um ambiente diferente em torno do corpo (como Vera Sala); seja partindo diretamente dos seus estados tônicos (como Cíntia Kunifas); seja, ainda, em várias dessas alternativas combinadas. Tirante o público que se afastou pela frustração em não ver ratificados os seus cânones estéticos, aquele que segue acompanhando a produção dos novos criadores aprecia o desafio proposto pelas novas configurações. O que é dança é uma questão que está sempre subjacente a esse tipo de trabalho, assim como o que é corpo e como ele funciona.

Este é o lugar da sinergia que queremos destacar entre a dança chamada pós-moderna e as práticas de educação somática. Essa sinergia não é homogênea como zona interdisciplinar de criação de conhecimento. Ela não envolve toda a dança, mas com certeza uma parcela importante formada por criadores que privilegiam a investigação da percepção do corpo e da organização do movimento como fonte importante para a sua criação de linguagem. Nosso intuito é ressaltar o quanto esses novos experimentos com o corpo em situação pedagógica resultaram em novas possibilidades expressivas, e vice-versa. $\mathrm{O}$ panorama geral é de desestabilização de noções importantes sobre corpo, memória e aprendizado.

\section{A Ciência na formação em dança}

Para terminar este artigo, eu gostaria de defender a ideia de que essa interface entre dança e educação somática como produtora de conhecimento sobre o corpo pode ser mais protagonizada por dançarinos, na forma de equipes interdisciplinares.

Falar da sinergia entre dança e educação somática implica necessariamente tratar de outra ainda maior, que é entre arte e ciência, lembrando que o prurido entre conhecimentos de naturezas diferentes é um fenômeno recente na história. A simples lembrança de Leonardo da Vinci (1452-1519) basta para reconhecer o potencial do encontro e rejeitar a separação disciplinar do conhecimento. 
Venho de uma formação mista entre dança e biologia e desde cedo tive interesse por estudos do corpo e do movimento, de modo que o meu pensamento sempre se fez, inevitavelmente, com informações dessas duas áreas, em um processo bidirecional. Desde o início de minha formação universitária em dança fui atraída para as leituras do campo da educação somática, com grande admiração pela possibilidade de lançar questôes experimentais sobre o corpo e o movimento, concomitantemente à pesquisa de linguagem em dança. Hoje, em minha atuação profissional como artista docente e pesquisadora, observo os resultados de como essa sinergia qualifica a prática educacional e instaura um modo particular de lançar questôes sobre a dança e sobre o corpo. Meu trabalho na universidade, atuando em um curso superior de arte, investe no desafio de desenvolver uma prática pedagógica que possa estimular a superar essa separação, de modo que certas perguntas que surgem durante a pesquisa de movimento suscitem explicações das ciências e a leitura de textos de ciência propóe novas questôes que serão investigadas na prática da dança. Tendo a acreditar que esta abordagem interdisciplinar venha ao encontro das atuais tendências da educação (Almeida, 2007) e da própria dança.

Por isso, defendo o lugar do conhecimento científico na formação do dançarino. Observo que existe uma polêmica muitas vezes velada que, na prática, produz atritos constantes. É bastante comum, nos cursos universitários de dança, os professores de técnica declararem sim, os dançarinos precisam saber anatomia, mas, na prática, as técnicas de dança e a análise do movimento permanecem isoladas uma da outra, seja por falta de disposição para interagir de uma parte ou da outra, ou de ambas. São raros os professores de anatomia e cinesiologia com abordagens específicas para dança e com disponibilidade de interagir com as aulas de técnica; ao mesmo tempo, é bastante comum os professores de técnica sentirem-se ameaçados pela cinesiologia, porque ela aumenta a capacidade crítica dos alunos.

Essa resistência reflete tanto o próprio medo de alguns agentes do campo da dança de lidarem com conhecimentos científicos e uma visão conservadora - que ainda sobrevive no meio, com suas crenças próprias do romantismo, tais como a de que a ciência atrapalha a criação —, quanto o preconceito de docentes das áreas científicas, que não acreditam que o artista possa produzir conhecimento qualificado sobre o corpo.

É importante frisar que, embora não saiba, ao formular uma aula de técnica de dança, um professor está formulando hipóteses sobre o que é dança, como o movimento se aprende, etc. Mesmo que os fundamentos que orientam a prática pedagógica de determinado professor sejam essencialmente filosóficos ou estéticos, os conhecimentos sobre análise do movimento estão implícitos quando ele propõe uma aula de técnica. Assim, é melhor que ele tenha conhecimentos necessários para tratar disso com consciência e competência. 
Fortin (1998) mostra que a fundamentação lógica que os professores dão às suas açōes é tão importante quanto seus comportamentos. A fundamentação lógica evidencia-se nos princípios organizadores fundamentais do ensino praticado pelo professor, ou seja, que princípios aparecem nas instruções aos alunos e como estas são transmitidas, sendo que eles se complementam como concepção de dança.

Não se justifica a rejeição à ciência por ignorância e desconhecimento, já que ela mesma já superou os paradigmas clássicos (Prigogine e Stengers, 1997). Ideias a respeito de temas tais como consciência, memória, mente e corpo ganharam importantes contribuiçōes no final do século XX, daí a necessidade de acompanhar esses debates.

Um desafio que precisa ser encarado com seriedade é tornar a ciência um conhecimento acessível nos currículos acadêmicos de dança, superando dificuldades que vão desde a falta de livros adequados ${ }^{15}$ até de profissionais capacitados para atuar em sinergia ${ }^{16}$. Nesse sentido, concordo com a educadora norte-americana Jill Green: a tendência de a educação somática tornar-se uma "nova área de estudo dentro da dança" ou uma "sub-disciplina em dança" é muito positiva no sentido de trazer o corpo de volta para a dança e para o currículo de formação do dançarino (Green, 2002, p. 113).

\section{Conclusão}

Muito se tem falado sobre a influência da educação somática nas práticas educacionais de dança, mas o potencial desse encontro particular entre a ciência e a arte de produzir conhecimento sobre o corpo vem sendo pouco explorado. Minha hipótese é de que esse encontro produz um ambiente de experimentação não só para a arte, mas também para teorias sobre o corpo.

Trata-se de um ambiente frutífero de experimentação que, se adequadamente aproveitado, pode tornar-se um subcampo importante de produção de conhecimento qualificado e original. Depende de consolidar-se cada vez mais como campo de natureza interdisciplinar.

O estudo dessa interface destaca-se também pelo interesse epistemológico, na medida em que evidencia a interação produtiva que ocorre entre conheci-

15. Um exemplo: a maioria dos livros sobre fisiologia humana disponíveis não traz nenhuma informação sobre assuntos como refinamento sensorial e modulação do tônus, temas centrais para falar de técnica para dança hoje. Para evitar a repetição esta substituição é possível?

16. Salvo raras exceções: o fato de ter sido aluna de José Antônio Lima, então professor de anatomia e cinesiologia aplicadas à dança no curso de graduação em dança da Unicamp, e o fato de ter participado de seu grupo de pesquisa do movimento na época em que ele investigava a criação de um novo método de educação do corpo para o movimento foram oportunidades centrais em minha formação. 
mentos de naturezas diferentes, ressaltando a ênfase na direção não disciplinar do conhecimento.

\section{Referências bibliográficas}

ALEXANDER, Gerda. Eutonia. São Paulo: Martins Fontes, 1991.

ALMEIDA, Naomar. Universidade nova. Textos críticos e esperançosos. Brasília. Editora da UnB, 2007.

ASLAN, Odette. Le corps en jeu. CNRS Editions, Paris, 1994.

BARTENIEFF, Ingmar; LEWIS, D.. Body movement: coping with the environment. New York: Gordon \& Breach, 1980.

DAMÁSIO, António. O mistério da consciência. São Paulo: Companhia das Letras, 2000.

DOUD, Irene. Métaphores du toucher. Nouvelles de danse. Bruxelas: Contradanse, n.. 29, p. 19-29, 1996. EDELMAN, Gerald. Biologia da consciência. Lisboa: Instituto Piaget, 1992.

FELDENKRAIS, Moshe. Awareness through movement. New York: Harper and Row, 1972.

FORTIN, Sylvie. L'education somatic et la formation en danse. Nouvelles de Danse. Bruxelas : Contradanse, n.. 28, p. 15-30, 1996.

FORTIN, Sylvie. Quando a ciência da dança e a educação somática entram na aula de técnica de dança. Pro-Posiçōes. Campinas: Editora da Unicamp, v.. 9, n., 2 (26), 1998.

FORTIN, Sylvie. Living in movement: devellopment of sommatic practices in different cultures. Journal of Dance Education. New Jersey, v.. 2, n.. 4, p. 128-136, 2002.

GODARD, Hubert. A propos des théories sur le mouvement. Marsyas. Paris, v. 16, p. 19-23, 1990.

GREINER, Christine. Butô - pensamento em evolução. São Paulo: Escrituras, 1998.

GREEN, Jill. Somatic Knowledge: the body as content and methodology in dance. Journal of Dance Education. New Jersey, v.. 2, n.. 4, p. 114-118, 2002.

HACKNEY, Peggy. Connexité et expressivité par les Bartenieff Fundamentals. Nouvelles de Danse. Bruxelas : Contradanse, n.. 28, p. 72-81, 1996.

LAKOFF, George ; JOHNSON, Mark. Philosophy in the flesh — the embodied mind and its challenge to Western Thought. New York: Basic Books, 1999.

LIMA, José António de Oliveira. O movimento humano: a práxis da corporalidade. Dissertação (Mestrado) - Faculdade de Educação da Universidade Estadual de Campinas, Campinas, 1994.

LIMA, José António de Oliveira. Educação somática: diálogos entre educação, saúde e arte no contexto da proposta da Reorganização Postural Dinâmica. Tese (Doutorado) — Faculdade de Educação da Universidade Estadual de Campinas, Campinas, 2010. 
LOUPPE, Laurence. L'utopie du corps indéterminé. In : ASLAN, Odette (Org.). Le corps en jeu. Paris: CNRS Editions, 1994.

MILLER, Jussara. A escuta do corpo — sistematização da técnica Klauss Vianna. São Paulo: Summus, 2007.

NEVES, Neide. Klauss Vianna : estudos para uma dramaturgia corporal. São Paulo: Editora Cortez, 2008.

PRIGOGINE, Ilya; STENGERS, Isabelle. A nova aliança: metamorfose da ciência. Brasília: Editora Universidade de Brasília, 1997. 247p.

TANI, Go; FREUDENHEIM, Andréa Michele; MEIRA JÚNIOR, Cássio de Miranda; CORRÊA, Umberto Cesar. Aprendizagem motora: tendências, perspectivas e aplicaçōes. Revista paulista de Educação Física, São Paulo, v.18, p.55-72, ago. 2004.

SACHS, Oliver. O homem que confundiu sua mulher com um chapéu. São Paulo: Companhia das Letras, 2001.

SMITH, N.S. Se mouvoir de l'interieur - un entertien avec Bonnie Bainbridge Cohen. Nouvelles de Danse Bruxelas : Contradanse, n.. 29, p. 30-43, 1996.

SMITH, Linda. Movement matters: the contributions of Esther Thelen. Biological Theory, v.1, n. 1, p. 87-89, 2006.

STRAZZACAPPA, Márcia. As técnicas corporais e a cena. In: GREINER, Christine e BIÃO, Armindo (Org.). Etnocenologia, textos selecionados. São Paulo: Annablume, 1998.

SWEIGARD, Lulu. Le mouvement imaginé. Nouvelles de Danse Bruxelas: Contradanse, n.. 28, p. 31-42. 1996.

THELEN, Esther; SMITH Linda. A dynamics systems approach to the devellopment of cognition and action. Cambridge: Bradford Books/MIT Press, 1994.

VISHNIVETZ, Berta. Eutonia, uma educação do corpo para o ser. São Paulo: Summus, 1995. TODD, Mabel E.. The Thinking Body. Princeton Book Company, 1980.

Recebido em 10 de março de 2010 e aprovado em 11 de maio de 2010. 